\title{
Lateral Asymmetry in Upper and Lower Limb Bioelectrical Impedance Analysis in Youth Tennis Players
}

\author{
Análisis de Asimetría Lateral de Impedancia Bioeléctrica de \\ Miembros Superiores e Inferiores en Jugadores Jóvenes de Tenis
}

\author{
Ales Filipcic*; Ivan Cuk* \& Tjasa Filipcic***
}

FILIPCIC, A.; CUK, I. \& FILIPCIC, T. Lateral asymmetry in upper and lower limb bioelectrical impedance analysis in youth tennis players. Int. J. Morphol., 34(3):890-895, 2016.

SUMMARY: Tennis is a sport that requires asymmetric movements of dominat limbs and may lead to an asymmetric distribution of muscle mass. The main aim of the presented study was to determine the volume and degree of lateral asymmetry of the upper and lower limbs in youth tennis players using a bioelectrical impedance analysis. T-test was applied to find differences between the dominant and non-dominant arm and the right and left leg and thigh in four age categories. There were no significant differences between the right and left leg lean mass in the 12 and under, 14 and under and 16 and under age groups, but there were significant differences between the dominant and non-dominant arm lean mass and arm circumferences in all four age groups. All young tennis players had greater lean mass and arm circumferences of the dominant limb. Tennis players in the 18 and under group had higher average values of right leg lean mass and the differences are statistically significant. There were significant differences between right and left thigh circumferences in all age groups. Findings show that it is possible with such a simple, non-invasive and quick procedure as bioelectrical impedance to determine asymmetry in tennis players.

KEY WORDS: Young tennis players; Asymmetry; Bioelectrical impedance analysis.

\section{INTRODUCTION}

Tennis is recognized as a sport where the load on the musculoskeletal system is distinctly unilateral. During every tennis stroke, the arm that holds the racket is only the last link of a kinetic chain involving the sequential activation of the trunk muscles to cause trunk rotation and flexion movements to facilitate the transfer moment from the legs and trunk to the arm and the racket (Elliott, 2006). More pronounced use of the tennis player's dominant side of the body causes many changes: muscle hypertrophy in specific body parts (Rogowski et al., 2008; Sanchis-Moysi et al., 2010a, 2010b, 2010c), muscle strength (Ireland et al., 2013; Sanchís-Moysi et al., 2010c) and flexibility (Okudaira et al., 2012; Oyama et al., 2008), muscle fibre type (SanchísMoysi et al., 2010c), bone mineral content (BMC) and bone mineral density (Sanchis-Moysi et al., 2010a, 2010b). Different methods have been used to analyse body composition (Filipcic et al., 2008; Pradas de la Fuente, 2013) and identify tennis players' asymmetries: traditional anthropometric measurements, dual energy X-ray absorptiometry (DXA), magnetic resonance imaging (MRI), $3 \mathrm{D}$ body scanner and bioelectrical impedance analysis (BIA).
BIA is an affordable, non-invasive and fast method for assessing body composition (Baumgartner, 1996; De Lorenzo et al., 2000; Kyle et al., 2001; Yamada et al., 2013). Recently, some studies suggested that BIA had acceptable validity for use in predicting the muscle volume of the upper arm (Miyatani et al., 2000), while measurements of body fat percentage had to be interpreted with caution (JenskySquires et al., 2008) and valid BIA devices produced body composition values similar to those collected with hydrostatic weighing and dual-energy X-ray absorptiometry (Moon, 2013).

Researchers have found significant side-to-side differences between dominant and non-dominant body sides and pointed out that such imbalance raises the risk of injury (Oyama et al.; Sanchis-Moysi et al., 2010a, 2010c; Sannicandro et al., 2014). Such differences are not only significant for tennis, but also sports which are supposed to be symmetrical e.g artistic gymnastics (Cuk et al., 2012). Thus, using anthropometric measurements Krawczyk et al. (1998) found reflected asymmetry in the forearm girth, arm

\footnotetext{
* University of Ljubljana, Faculty of Sport, Ljubljana, Slovenia.

** University of Ljubljana, Faculty of Education, Ljubljana, Slovenia.
} 
girth and elbow width of male tennis players, while Brosseau et al. (2006) found that the total volume of the dominant upper limb of youth tennis players was $7.8 \%$ larger than the non-dominant one, while the dominant forearm had a 12.6 $\%$ greater mass than the non-dominant forearm. Sannicandro et al., found positive effects of six weeks of balance training on lowering the lower-limb strength asymmetry in youth tennis players.

The main aim of the presented study was to determine the volume and degree of lateral asymmetry of the upper and lower limbs in youth tennis players using a bioelectrical impedance analysis. Based on the conclusions of previous studies, we expected that use of BIA would also allow us to determine whether there are typical differences between dominant and non-dominant upper limbs in young tennis players.

\section{MATERIAL AND METHOD}

The data presented in this study were gathered as part of annual testing and screening in 2013 and 2014 at the Faculty of Sport, University of Ljubljana, organized by the Slovenian Tennis Association. Candidates for junior national teams and promising young tennis players aged 11 to 18 appearing on the national ranking list were included.

The study was conducted in accordance with the ethical standards outlined in the 1964 Declaration of Helsinki, following the 6th revision of 2008. Participation was based on written applications filed by clubs and coaches. Individual athletes and their parents received information about the study before the tests, and we obtained their consent before collecting the data.

The study included 259 players, 13 of whom were left-handed, which was taken into consideration in determining the dominant arm. The sample was composed of 100 male and female tennis players in the category 12 and under (age 11.29 \pm 0.77 , body mass $40.31 \pm 7.51$, body height 151.52 \pm 8.14 , BMI 17.42 \pm 1.93$), 49$ male and female tennis players in the category 14 and under (age $13.01 \pm 0.32$, body mass $49.08 \pm 7.76$, body height

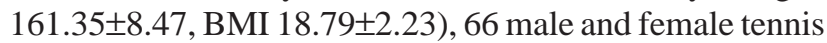
players in the category 16 and under (age $14.44 \pm 0.52$, body mass $57.73 \pm 7.65$, body height $170.44 \pm 6.33$, BMI $19.82 \pm 1.90)$ and 44 male and female tennis players in the category 18 and under (age $16.35 \pm 0.62$, body mass 68.45 \pm 8.66 , body height $177.83 \pm 6.81$, BMI 21.59 \pm 1.95 ). All participants trained regularly. We collected data on the number of years each had played tennis, the number and duration of Tennis, Fitness and Conditioning Sessions per week, and the number of tournaments played per year. In addition, the bioelectrical impedance measurement were performed.

Body height (BH) was measured with a stadiometer (Seca 220, Seca Corporation, Hamburg, Germany) while body mass, body mass index, dominant and non-dominant arm lean mass, dominant and non-dominant arm circumference, right and left leg lean mass, and right and left thigh circumference were measured with octopolar bioimpedance InBody 720 (Biospace, Seoul, Korea). The validity of this bioimpedance has been documented in studies (Medici et al., 2005; Ogawa et al., 2011). This technology enables the researcher to analyse five basic body parts independently: the left and right upper limb, trunk, and left and right lower limb, using frequencies of 1, 5, 50, 250, 500 and $1000 \mathrm{kHz}$.

Data analysis was performed using the SPSS 21.0 package (SPSS Inc., Chicago, USA) and a p-value of $\leq 0.05$ was considered for statistical significance. For verification of normality we used the Kolmogorov-Smirnov test. For variables with a normal distribution we used the paired T-test to determine the differences between the dominant and nondominant arm and the right and left leg and thigh. The test was applied separately for each age group. For variables with an abnormal distribution, we used the non-parametric Wilcoxon test.

\section{RESULTS}

The data on the tennis characteristics of the four age groups are presented in Table I and Figure 1. As expected, the Number of Years Playing Tennis, duration of Tennis Sessions per week and number of Fitness and Conditioning sessions per week increase through the age groups. This is not the case with Tennis Sessions per week, where 16 and under tennis players (4.9 sessions) train on average slightly less than tennis players two years younger (5.1 sessions). In 14 and under players, the weekly number of Fitness and Conditioning training sessions is lower $(2.7 \mathrm{~h})$ than in younger tennis players $(3.6 \mathrm{~h})$. The number of tournaments played per year rises significantly from the 12 and under (14.4 tournaments) to the 14 and under age category (18.6 tournaments) and decreases in the 18 and under group to 17.8 tournaments per year.

The data from the BIA measurements are presented in Table II. There were no significant differences between the right and left leg lean mass in the 12 and under, 14 and 
Table I. Tennis characteristics of young player in four age categories.

\begin{tabular}{lcccc}
\hline & 12 and under & $\mathbf{1 4}$ and under & $\mathbf{1 6}$ and under & $\mathbf{1 8}$ and under \\
\hline Year Playing Tennis & 4.9 & 6.0 & 7.7 & 10.1 \\
Tennis Session (week) & 3.8 & 5.1 & 4.9 & 5.9 \\
Tennis Session hours (week) & 5.9 & 8.4 & 9.1 & 11.0 \\
Fitness \& Conditioning Sessions (week) & 1.5 & 2.3 & 3.2 & 3.3 \\
Fitnees \& Conditioning hours (week) & 3.6 & 2.7 & 3.6 & 4.4 \\
Tournament (year) & 14.4 & 18.6 & 18.6 & 17.8 \\
\hline
\end{tabular}

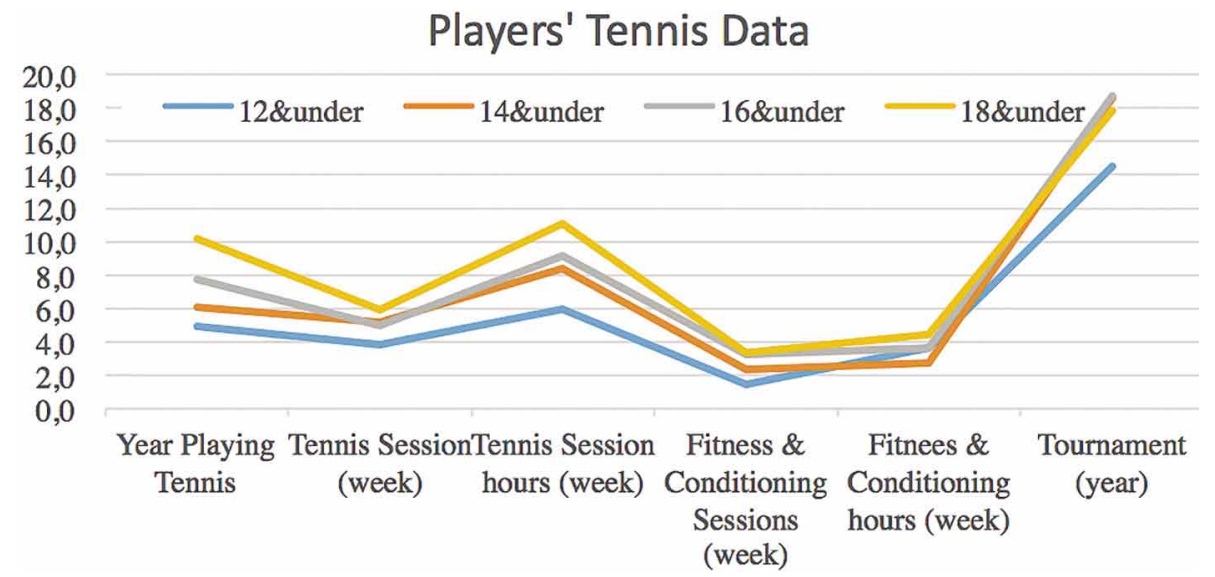

Fig. 1. Average values of tennis characteristics in four age categories.

Table II. Measurements of dominant and non-dominant arm, right and left leg lean mass and circumferences.

\begin{tabular}{|c|c|c|c|c|c|c|c|c|c|c|c|c|}
\hline \multirow{2}{*}{$\begin{array}{l}\text { Category } \\
\text { Pair }\end{array}$} & \multicolumn{3}{|c|}{12 and under } & \multicolumn{3}{|c|}{14 and under } & \multicolumn{3}{|c|}{16 and under } & \multicolumn{3}{|c|}{18 and under } \\
\hline & Mean & SD & $p$ & Mean & SD & $p$ & Mean & SD & $p$ & Mean & SD & $p$ \\
\hline \multirow{2}{*}{$\begin{array}{l}\text { Dominant Arm Lean Mass - Non- } \\
\text { dominant Arm Lean Mass }\end{array}$} & 1.61 & & \multirow{2}{*}{$0.00^{*}$} & 2.25 & 0.54 & \multirow{2}{*}{$0.00^{*}$} & 2.75 & 0.65 & \multirow{2}{*}{$0.00^{*}$} & 3.46 & 0.67 & \multirow{2}{*}{$0.00^{*}$} \\
\hline & 1.52 & 0.42 & & 2.11 & 0.49 & & 2.61 & 0.60 & & 3.31 & 0.63 & \\
\hline \multirow{2}{*}{$\begin{array}{l}\text { Dominant Arm Circumference - Non- } \\
\text { dominant Arm Circumference }\end{array}$} & 23.28 & 2.60 & \multirow{2}{*}{$0.00 *$} & 26.18 & 2.68 & \multirow{2}{*}{$0.00^{*}$} & 27.83 & 2.44 & \multirow{2}{*}{$0.00^{*}$} & 30.19 & 2.23 & \multirow{2}{*}{$0.00^{*}$} \\
\hline & 23.07 & 2.51 & & 25.52 & 2.43 & & 27.19 & 2.36 & & 29.64 & 1.93 & \\
\hline \multirow{2}{*}{$\begin{array}{l}\text { Right Leg Lean Mass - Left Leg Lean } \\
\text { Mass }\end{array}$} & 5.23 & 1.12 & \multirow{2}{*}{0.76} & 6.72 & 1.36 & \multirow{2}{*}{0.16} & 8.19 & 1.37 & \multirow{2}{*}{0.16} & 9.71 & 1.42 & \multirow{2}{*}{$0.00^{*}$} \\
\hline & 5.22 & 1.11 & & 6.70 & 1.35 & & 8.18 & 1.35 & & 9.65 & 1.38 & \\
\hline Right & 43.18 & 2.51 & \multirow{2}{*}{$0.00^{*}$} & 45.63 & 3.08 & \multirow{2}{*}{$0.00^{*}$} & 48.15 & 2.55 & \multirow{2}{*}{$0.00^{*}$} & 51.24 & 2.65 & \multirow{2}{*}{$0.00^{*}$} \\
\hline eft Thigh Circumference & 43.21 & 2.58 & & 45.69 & 3.12 & & 48.20 & 2.55 & & 51.32 & 2.73 & \\
\hline
\end{tabular}

Note: Mean, SD for age category, $*=p<0.05$.

under and 16 and under age groups, but there were significant differences between the dominant and non-dominant arm lean mass and arm circumferences in all four age groups. All young tennis players had greater lean mass and arm circumferences of the dominant limb. Tennis players in the
18 and under group had higher average values of right leg lean mass and the differences are statistically significant. There were significant differences between right and left thigh circumferences in all age groups. The average values of the left leg circumference were higher. 


\section{DISCUSSION}

Young tennis players in all four age groups have significantly higher dominant arm lean mass, which varies among the different age groups from being $4.4 \%$ to $6.4 \%$ higher. This result is in line with previous conclusions (Brosseau et al.; Sanchis-Moysi et al., 2010a, 2010c; Yamada et al.). Brosseau et al. conclude that in side-to-side comparisons the dominant arm lean mass was 6-8\% greater than the non-dominant arm. Yamada et al., conclude that tennis players in particular have a remarkably greater ratio of dominant as compared to non-dominant lean mass in the upper arms (12.54 $\pm 5.88 \%)$ and forearms $(10.38 \pm 4.35 \%)$. Sanchis-Moysi et al. (2010a, 2010c) found in two studies that inter-arm asymmetry in lean mass is even higher and amounts to $12-15 \%$, which is connected with an increase of muscle volume in the dominant arm compared to the nondominant arm as a result of hypertrophy of loaded muscle groups (deltoid, triceps brachii, arm flexors and forearm superficial flexor muscles) during the execution of tennis strokes. This is particularly the case with all forehand shots and with serving. Fleising et al. (2003) find that the serve is the most strenuous stroke on the upper limb, while Kibler (1995) notes that over half of the total force developed during the serve is generated from the lower extremity and trunk musculature. By analysing the workload of top tennis players in Grand Slam tournaments, Johnson et al. (2006) showed that from the total number of strokes in serve games as much as $45 \%$ (French Open) to $60 \%$ (Wimbledon) are serves. The winner of the U.S. Open hit over 1,000 serves in 120 serve games during the tournament.

The ratio/differences between the dominant and nondominant arm circumference is significant in all age groups, although the differences are not as distinct as in lean mass and vary from $0.99 \%$ to $2.55 \%$. Similar conclusions were made by Brosseau, et al. who, based on five conventionally measured anthropometric variables, then calculated the total upper limb circumference and found significant differences between dominant and non-dominant arms. Krawczyk et al. found among nine analysed sports that the most pronounced asymmetry was in tennis players (forearm girth, arm girth, elbow width).

The significantly larger lean mass and increased arm circumference in all four age groups of young tennis players is consistent with increased specific loads, which is shown through an increased number and extent of tennis trainings per week. The weekly scope of tennis training sessions in the 12 and under category is $5.9 \mathrm{~h}$ and grows to $11 \mathrm{~h}$ in the 18 and under category. The number of tennis tournaments also rises significantly with age from 14.4 to 17.8 tournaments per year. On the other hand, the number and extent of Fitness and Conditioning training sessions, which can have an important corrective function in reducing the effects of a one-sided load (Krawczyk et al.), are not as pronounced.

Previous studies of asymmetry in tennis players have dealt with differences between dominant and non-dominant upper limbs and to a lesser extent addressed the differences in lower limbs. In lower limbs, it is more difficult to define the dominant body extremity and determining the load of individual body segments is only possible when considering the loads arising from analysis of the tennis game. In our study, the right and left leg lean mass was similar in three age categories; significant but very small $(0.59 \%)$ differences were only detected in the 18 and under age category. This finding is consistent with the finding of a study by Yamada, et al., who detected differences in segmental muscle volumes of thighs and lower legs. In all four observed age groups, there are significant differences in right and left thigh circumference; left thigh circumference is $0.07 \%$ to $0.15 \%$ bigger. The reasons for the thigh circumference differences can be explained by the load of tennis players.

The load of tennis players in terms of the number of executed shots shows that, on clay, tennis players on average play 21 shots when serving and 14.8 when returning (Johnson et al.). In serve games, there are 6.5 first and $2.4 \mathrm{~s}$ serves, the number of topspin forehands on average amounts to 6 , while topspin backhands average out at 4.2. In return games, there are on average 2.8 forehand returns and 3 backhand returns. On the baseline, players execute more topspin backhands (3.7) than topspin forehands (3.2). Biomechanical analysis of the serve (Elliott et al., 2003; Fleisig et al.), forehand (Reid et al., 2013) and backhand (Genevois et al., 2015) is based on the assumption of ballistic shots, where all body segments are included in the implementation. Legs as the first part of the kinetic chain have an extremely important role in movement, positioning, beginning of the shot and recovery after the shot. The left leg (in a right-handed player), in particular, has an important role in the leg drive serve (knee flexion - extension) and also in the topspin backhand (body weight transfer from the left to right leg), especially if the backhand, which players on the baseline are hitting more often, is executed from an open stance.

Body asymmetry is a common occurrence in tennis players, but there are ways to reduce it. Sannicandro et al., significantly reduced the asymmetry of lower limbs with a 
specific balance-training programme which they performed with tennis players for 6 weeks. In this way, they suggested that the solution to reduce asymmetry in tennis players is appropriately comprehensive; properly planned and implemented fitness and conditioning training with clear preventive/corrective objectives must be carried out from the start of practising tennis.

\section{CONCLUSIONS}

The present results show that body asymmetry in tennis players is already present from the youngest period onwards. Tennis players in the 12 \& under category are actively involved in tennis training for almost 5 years, i.e. since their seventh year of age. Loads in the majority of tennis strokes are highly ballistic and unilateral and, in addition, the number of repetitions is extremely high. The loads and pressures during a tennis match are only the tip of the iceberg; hiding underneath is the even larger number of executed strokes in tennis trainings. We should not neglect the importance of optimal techniques which reduce the risk of injuries; on the other hand, poorly developed techniques and a large number of repetitions are very likely to result in injury.

Our findings show that it is possible with such a simple, non-invasive and quick procedure as bioelectrical impedance to determine asymmetry in tennis players. We are aware that with an even more precise determination of the differences between individual body segments (e.g. upper arm, forearm), we could create targeted fitness and conditioning training for young tennis players. With the correlation of data on body asymmetry and data on the number, type and duration of injuries of tennis players, we can determine not only how a one-sided load influences the occurrence of injuries, but also how the number, scope and type of prevention programmes can reduce body asymmetry and thereby decrease the incidence of injury.

FILIPCIC, A.; CUK, I. \& FILIPCIC, T. Análisis de asimetría lateral de impedancia bioeléctrica de miembros superiores e inferiores en jugadores jóvenes de tenis. Int. J. Morphol., 34(3):890-895, 2016.

RESUMEN: El tenis es un deporte que requiere movimientos asimétricos de los miembros dominantes y puede conducir a una distribución asimétrica de la masa muscular. El objetivo fue determinar el volumen y grado de asimetría lateral de los miembros superiores e inferiores en tenistas juveniles utilizando un análisis de impedancia bioeléctrica. Se aplicó la prueba T para encontrar diferencias entre el brazo dominante y no dominante y las piernas y muslos derecho e izquierdo en cuatro categorías de edad. No hubo diferencias significativas en la masa magra de las piernas derecha e izquierda en los grupos de edad: 12 y menor, 14 y menor, y 16 y menor. Sin embargo, hubo diferencias significativas en la masa magra de las circunferencias de los brazos dominante y no dominante en los cuatro grupos de edad. Todos los jugadores jóvenes de tenis tenían mayor masa magra en las circunferencias de los brazos del miembro dominante. Los jugadores de tenis en el grupo de 18 años y menor, tenían valores medios más altos de masa magra de la pierna derecha, con diferencias estadísticamente significativas. No hubo diferencias significativas entre las circunferencias de los muslos derecho e izquierdo en todos los grupos de edad. Los resultados muestran que es posible determinar con un procedimiento simple no invasivo y rápido, como la impedancia bioeléctrica, la asimetría en jugadores de tenis.

\section{PALABRAS CLAVE: Jugadores jóvenes de tenis; Asimetría; Análisis de impedancia bioeléctrica.}

\section{REFERENCES}

Baumgartner, R. N. Electrical Impedance and Total Body Electrical Conductivity. In: Roche, A. F.; Heymsfield, S. B. \& Lohman, T. G. (Eds.). Human Body Composition. Champaign, Human Kinetics, 1996. pp. 79-107.

Brosseau, O.; Hautier, C. \& Rogowski, I. A field study to evaluate side-to-side differences in the upper limbs of young tennis players. Med. Sci. Tennis, 11(1):18-9, 2006.

Cuk, I.; Pajek, M. B.; Jakse, B.; Pajek, J. \& Pecek, M. Morphologic bilateral differences of top level gymnasts. Int. J. Morphol., 30(1):110-4, 2012.
De Lorenzo, A.; Bertini, I.; Iacopino, L.; Pagliato, E.; Testolin, C. \& Testolin, G. Body composition measurement in highly trained male athletes. A comparison of three methods. J. Sports Med. Phys. Fitness,40(2):178-83, 2000.

Elliott, B. Biomechanics and tennis. Br. J. Sports Med., 40(5):3926, 2006.

Elliott, B.; Fleisig, G.; Nicholls, R. \& Escamilia, R. Technique effects on upper limb loading in the tennis serve. J. Sci. Med. Sport, 6(1):76-87, 2003. 
Filipcic, A.; Leskosek, B.; Sarabon, N. \& Filipcic, T. Secular trends in body dimensions among young tennis players from 1992 to 2008. Int. J. Morphol., 30(4):1558-68, 2012.

Fleisig, G.; Nicholls, R.; Elliot, B. \& Escamilla, R. Kinematics used by world class tennis players to produce high-velocity serves. Sports Biomech., 2(1):51-64, 2003.

Genevois, G.; Reid, M.; Rogowski, I. \& Crespo, M. Performance factors related to the different tennis backhand groundstrokes: a review. Sports Sci. Med., 14(1):194-202, 2015.

Ireland, A.; Maden-Wilkinson, T.; McPhee, J.; Cooke, K.; Narici, M.; Degens, H. \& Rittweger, J. Upper limb muscle-bone asymmetries and bone adaptation in elite youth tennis players. Med. Sci. Sports Exerc., 45(9):1749-58, 2013.

Jensky-Squires, N. E.; Dieli-Conwright, C. M.; Rossuello, A.; Erceg, D. N.; McCauley, S. \& Schroeder, E. T. Validity and reliability of body composition analysers in children and adults. Br. J. Nutr., 100(4):859-65, 2008.

Johnson, C. D.; McHugh, M. P.; Wood, T. \& Kibler, B. Performance demands of professional male tennis players. $\mathrm{Br} . \mathrm{J}$. Sports Med., 40(8):696-9, 2006.

Kibler, W. B. Biomechanical analysis of the shoulder during tennis activities. Clin. Sports Med., 14(1):79-85, 1995.

Krawczyk, B.; Sklad, M.; Majle, B. \& Jackiewicz, A. Lateral asymmetry in upper and lower limb measurements in selected groups of male athletes. Biol. Sport, 15(1):33-8, 1998.

Kyle, U. G.; Genton, L.; Karsegard, L.; Slosman, D. O. \& Pichard, C. Single prediction equation for bioelectrical impedance analysis in adults aged 20--94 years. Nutrition, 17(3):248$53,2001$.

Medici, G.; Mussi, C.; Fantuzzi, A. L.; Malavolti, M.; Albertazzi, A. \& Bedogni, G. Accuracy of eight-polar bioelectrical impedance analysis for the assessment of total and appendicular body composition in peritoneal dialysis patients. Eur. J. Clin. Nutr., 59(8):932-7, 2005.

Miyatani, M.; Kanehisa, H. \& Fukunaga, T. Validity of bioelectrical impedance and ultrasonographic methods for estimating the muscle volume of the upper arm. Eur. J. Appl. Physiol., 82(5-6):391-6, 2000.

Moon, J. R. Body composition in athletes and sports nutrition: an examination of the bioimpedance analysis technique. Eur. J. Clin. Nutr., 67(Suppl. 1):S54-9, 2013.

Ogawa, H.; Fujitani, K.; Tsujinaka, T.; Imanishi, K.; Shirakata, H.; Kantani, A.; Hirao, M.; Kurokawa, Y. \& Utsumi, S. InBody 720 as a new method of evaluating visceral obesity. Hepatogastroenterology, 58(105):42-4, 2011.
Okudaira, S.; Nakata, K.; Sato, M.; Yoshimoto, Y. \& Beppu, M. Physical characteristics of male competitive tennis players in the Japan national team: side-to-side differences in the range of motion and lower extremity muscle tightness. J. Jpn. Soc. Clin. Sports Med., 20(3):510-5, 2012.

Oyama, S.; Myers, J. B.; Wassinger, C. A.; Daniel Ricci, R. \& Lephart, S. M. Asymmetric resting scapular posture in healthy overhead athletes. J. Athl. Train., 43(6):565-70, 2008.

Pradas de la Fuente, F.; Gonzales Jurado, J. A.; Molina Sotomayor, E. \& Castellar Otin, C. Anthropometric characteristics, body composition and somatotype of high level table tennis players. Int. J. Morphol., 31(4):1355-64, 2013.

Reid, M.; Elliott, B. \& Crespo, M. Mechanics and learning practices associated with the tennis forehand: a review. J. Sports Sci. Med., 12(2):225-31, 2013.

Rogowski, I.; Ducher, G.; Brosseau, O. \& Hautier, C. Asymmetry in volume between dominant and nondominant upper limbs in young tennis players. Pediatr. Exerc. Sci., 20(3):263-72, 2008.

Sanchis-Moysi, J.; Idoate, F.; Dorado, C.; Alayón, S. \& Calbet, J. A. Large asymmetric hypertrophy of rectus abdominis muscle in professional tennis players. PLoS One, 5(12):e15858, 2010a.

Sanchis-Moysi, J.; Dorado, C.; Olmedillas, H.; Serrano-Sanchez, J. A. \& Calbet, J. A. Bone mass in prepubertal tennis players. Int. J. Sports Med., 31(6):416-20, 2010 b.

Sanchís-Moysi, J.; Idoate, F.; Olmedillas, H.; Guadalupe-Grau, A.; Alayón, S.; Carreras, A.; Dorado, C. \& Calbet, J. A. The upper extremity of the professional tennis player: muscle volumes, fiber-type distribution and muscle strength. Scand. J. Med. Sci. Sports, 20(3):524-34, 2010c.

Sannicandro, I.; Cofano, G.; Rosa, R. A. \& Piccinno, A. Balance training exercises decrease lower-limb strength asymmetry in young tennis players. J. Sports Sci. Med., 13(2):397-402, 2014.

Yamada, Y.; Yamashita, D.; Yamamoto, S.; Matsui, T.; Seo, K.; Azuma, Y.; Kida, Y.; Morihara, T. \& Kimura, M. Whole-body and segmental muscle volume are associated with ball velocity in high school baseball pitchers. Open Access J. Sports Med., 4:89-95, 2013.

Correspondence to:

Dr. Ales Filipcic

University of Ljubljana

Faculty of Sport

Gortanova 22

1000 Ljubljana

SLOVENIA

Received: 25-09-2015

Accepted: 22-04-2016

Email: ales.filipcic@fsp.uni-lj.si 